\title{
Dopamine Excites Nucleus Accumbens Neurons through the Differential Modulation of Glutamate and GABA Release
}

\author{
Gregory 0. Hjelmstad \\ Department of Neurology, Wheeler Center for the Neurobiology of Addiction and the Ernest Gallo Clinic and Research Center, University of California San \\ Francisco, Emeryville, California 94608
}

\begin{abstract}
Afferent activity into the nucleus accumbens (NAc) occurs in bursts of action potentials. However, it is unclear how synapses in this nucleus respond to such bursts, or how these responses are altered by dopamine (DA). I examined the effects of DA on excitatory and inhibitory responses to trains of stimuli in rat NAc slices. Both EPSCs and IPSCs showed use-dependent depression during trains. Although DA inhibited both glutamate and GABA release in the NAc, it differentially inhibited release during trains. The inhibition of IPSCs persisted throughout the train of stimuli, whereas the inhibition of EPSCs progressively diminished. This differential modulation may be explained by a calcium-dependent change in the recovery from depression at the GABA synapses, where DA acts by decreasing $\mathrm{Ca}^{2+}$ entry. Thus, at later stages of sustained stimulation, DA preferentially inhibits GABA release, producing a net excitatory effect during bursts suggesting a mechanism for enhancing the contrast between competing inputs into the NAc, as well as for affecting long-term plasticity in this structure.
\end{abstract}

Key words: accumbens; dopamine; depression; burst; presynaptic; calcium

\section{Introduction}

The nucleus accumbens (NAc), a part of the ventral striatum, is involved in cue-related reward behaviors, including maladaptive behaviors associated with drugs of abuse. Dopamine (DA) plays a critical role in this, presumably by enhancing cue-driven inputs into the NAc, which helps to facilitate the selection of an appropriate behavioral response. Recent studies support the hypothesis that DA neuron firing encodes an "error signal" (Schultz, 1998): DA neurons fire in response to unexpected rewards and to cues that are predictive of reward. The role of this DA is twofold (McClure et al., 2003). First, DA promotes the selection of an appropriate behavior to acquire the predicted reward. Second, DA release contributes to reinforcement by associating predictive cues with specific outcomes. In support of these ideas, rewardpredictive cues excite a subset of NAc neurons (Ghitza et al., 2003; Nicola et al., 2004a), and inactivating DA neurons reduces these excitations in the NAc (Yun et al., 2004). However, the cellular mechanisms underlying how DA excites NAc neurons are unclear.

DA directly modulates a number of postsynaptic conductances in both the NAc and the dorsal striatum (Nicola et al., 2000; Hopf et al., 2003). In addition, in contrast to the dorsal striatum (Nicola and Malenka, 1998), DA robustly inhibits both glutamate and GABA release in the NAc (Pennartz et al., 1992;

\footnotetext{
Received June 9, 2004; revised Aug. 24, 2004; accepted Aug. 24, 2004.

This work was supported by National Institute on Drug Abuse Grant DA-15686 and by funds provided by the State of California for medical research on substance abuse through University of California San Francisco. I thank Drs. H. Fields and S. Nicola for helpful comments on this manuscript.

Correspondence should be addressed to G. 0. Hjelmstad, 5858 Horton Street, Suite 200, Emeryville, CA 94608. E-mail: gregh@egcrc.net.

DOI:10.1523/JNEUROSCI.3280-04.2004

Copyright $\odot 2004$ Society for Neuroscience $\quad 0270-6474 / 04 / 248621-08 \$ 15.00 / 0$
}

Nicola and Malenka, 1997). This presynaptic inhibition is particularly important for understanding how DA affects NAc neurons, because the projecting medium spiny neurons (MSNs) have hyperpolarized resting membrane potentials (Uchimura et al., 1989) and do not fire in the absence of excitatory afferent activity. Thus, it is unclear how DA can excite MSNs when one of its primary effects is to inhibit glutamate release, the very transmitter required to produce activity.

The NAc receives excitatory glutamatergic afferents from prefrontal cortex, hippocampus, and amygdala (Pennartz et al., 1994). This afferent activity provides cue-related information to the nucleus. Furthermore, these excitatory afferents recruit a GABAergic feedforward inhibition onto MSNs both through interneurons and through axon collaterals of neighboring MSNs (Chang and Kitai, 1985; Pennartz and Kitai, 1991; Kawaguchi et al., 1995; Taverna et al., 2004). Neurons that project to the NAc burst during relevant behaviors (Cooper, 2002). For example, subpopulations of layer $\mathrm{V}$ neurons in the monkey prefrontal cortex respond with a burst during various phases of a goal-directed task (Schultz et al., 2000). In the rat, the instantaneous frequency during these bursts can exceed $50 \mathrm{~Hz}$ (Jung et al., 1998). Depending on the brain region, synapses respond to bursts of activity with facilitation, depression, or a combination of these two forms of short-term plasticity (Markram et al., 1998; Dittman et al., 2000; Zucker and Regehr, 2002). However, in the NAc, it is unknown how bursts of activity affect neurotransmitter release. Moreover, it is unclear how neuromodulators such as DA affect this presynaptic short-term plasticity.

Here, I have investigated the effects of DA on trains of synaptic activity at both glutamatergic and GABAergic synapses in the NAc. Although there is frequency-dependent depression of release at both types of synapses, DA differentially affects glutamate 
and GABA responses. DA inhibited the initial EPSC or IPSC of a train. However, the DA inhibition of the IPSC persisted throughout the train, whereas the inhibition of the EPSC progressively diminished. This differential modulation of release results in a net excitatory effect on MSNs under burst-firing conditions and points to a novel mechanism for explaining the functional effect of DA in the NAc.

\section{Materials and Methods}

Two- to 4-week-old male Sprague Dawley rats were anesthetized with isoflurane, decapitated and the brain removed, and placed into an icecold Ringer's solution $\left(\sim 3^{\circ} \mathrm{C}\right.$ ) containing (in $\mathrm{mm}$ ): $119 \mathrm{NaCl}, 2.5 \mathrm{KCl}, 1.3$ $\mathrm{MgSO}_{4}, 1.0 \mathrm{NaH}_{2} \mathrm{PO}_{4}, 2.5 \mathrm{CaCl}_{2}, 26.2 \mathrm{NaHCO}_{3}$, and 11 glucose saturated with $95 \% \mathrm{O}_{2}-5 \% \mathrm{CO}_{2}$. Coronal slices $(350-\mu \mathrm{m}$-thick) containing the NAc were cut using a vibratome (Leica, Nussloch, Germany). Slices were submerged in Ringer's solution and allowed to recover for $>1$ hr at $29^{\circ} \mathrm{C}$.

Individual slices were transferred to a poly-D-lysine-coated coverslip and visualized under an Olympus Optical (Melville, NY) upright microscope with differential interference contrast optics and infrared illumination. Slices were perfused with Ringer's solution at $27^{\circ} \mathrm{C}$. Whole-cell patch-clamp recordings were made from MSNs using 2.5-4 $\mathrm{M} \Omega$ pipettes containing (in mM): 123 Cs-gluconate, $10 \mathrm{HEPES}, 0.2 \mathrm{EGTA}, 8 \mathrm{NaCl}, 2$ MgATP, and $0.3 \mathrm{Na}_{3} \mathrm{GTP}, \mathrm{pH} 7.2$, osmolarity adjusted to 280 . In some experiments, GTP was replaced with $1 \mathrm{~mm}$ GDP- $\beta$ S. Cells were identified as MSNs by their appearance and by their hyperpolarized resting potential (Uchimura et al., 1989). Neurons were voltage clamped at $-80 \mathrm{mV}$. Trains of EPSCs or IPSCs were evoked (10-50 Hz trains given 15-30 sec apart) with a bipolar stimulating electrode placed in the NAc shell dorsal to the recording site.

Recordings were made using an Axopatch 1-D (Axon Instruments, Foster City, CA) amplifier and were filtered at $2 \mathrm{kHz}$ and collected at 5 $\mathrm{kHz}$ using Igor Pro (Wavemetrics, Lake Oswego, OR). Series resistance was monitored on-line by measuring the peak of the capacitance transient in response to a $-4 \mathrm{mV}$ voltage step applied before each stimulus. Amplitudes were calculated by comparing a $1 \mathrm{msec}$ period at the peak of the response and a similar period just before the stimulus artifact for the initial response. On subsequent responses in the train, a two-exponential fit of the decay of the previous PSC was made. The amplitude of the response was then calculated as the value of a $1 \mathrm{msec}$ period at the peak compared with the value of the extrapolated curve at that same time. For experiments looking at recovery from depression, test pulses at four different intervals $(100,200,400$, and $800 \mathrm{msec})$ were interleaved throughout the experiment under control of procedures written in Igor Pro. Similarly, in some experiments, trains at different frequencies were interleaved throughout the experiment.

All drugs were applied by bath perfusion. Stock solutions were made and diluted to a final concentration in Ringer's immediately before application. D-APV (50 $\mathrm{mm}$ ) and $R(+)$-7-chloro-8-hydroxy-3-methyl-1phenyl-2,3,4,5-tetrahydro-1H-3-benzazepine hydrochloride ( $\mathrm{SCH}$ 23390 ) were diluted in $\mathrm{H}_{2} \mathrm{O}$, sulpiride ( $10 \mathrm{~mm}$ ) was diluted in $\mathrm{ETOH}$, and DNQX (10 mM) and picrotoxin (100 mM) were mixed in DMSO. Stock solution of DA ( $75 \mathrm{~mm}$ ) was made daily in $50 \mathrm{~mm}$ sodium metabosulfite. Chemicals were obtained from Sigma (St. Louis, MO) or Tocris Cookson (Ballwin, MO). In experiments using GDP- $\beta$ S, at least $20 \mathrm{~min}$ was allowed before application of DA to ensure that the cell was properly dialyzed.

The coefficient of variation (CV) was calculated as the $\mathrm{SD} /$ mean amplitude for 20 consecutive sweeps in each condition. Unless otherwise noted, statistical analyses were performed using Student's $t$ test, and significance was defined at $p<0.05$. Results are presented as means \pm SEM.

The integrate-and-fire-simulated neuron was modeled by the following differential equation:

$\frac{d V_{\mathrm{m}}}{d t}=\left(g_{\mathrm{EPSC}} \times R_{\mathrm{i}} \times\left(0-V_{\mathrm{m}}\right)+g_{\mathrm{IPSC}} \times\right.$

$\left.R_{\mathrm{i}} \times\left(-60-V_{\mathrm{m}}\right)+\left(V_{\text {rest }}-V_{\mathrm{m}}\right)\right) / \tau_{\mathrm{m}}$,

A

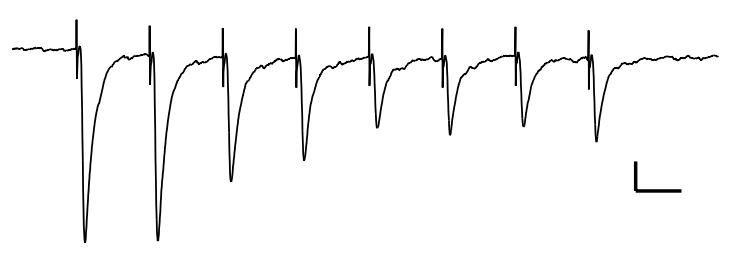

B

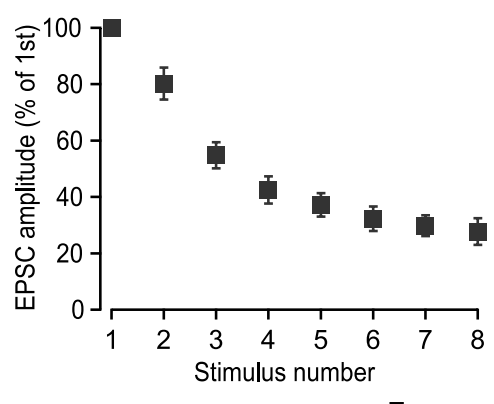

D

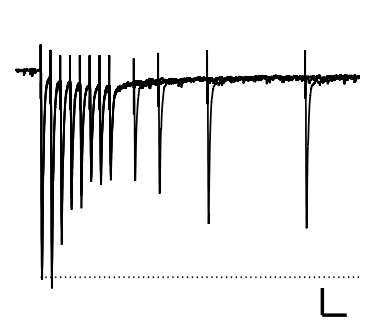

$E$

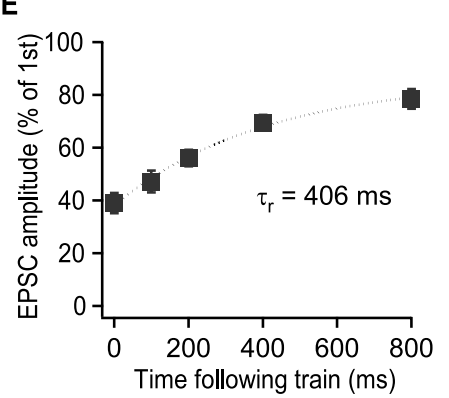

Figure 1. EPSCS show short-term depression in response to a train. $A$, Example of a train of EPSCS (8 stimuli at $25 \mathrm{~Hz}$ ) illustrating short-term depression at this synapse. Calibration: $50 \mathrm{pA}$, $25 \mathrm{msec} . B$, Average of responses for eight cells. C, In six cells in which trains of stimuli at three different frequencies were interleaved, the amount of short-term depression is frequency dependent (repeated-measures ANOVA; $p<0.001$ ). D, Example of recovery from short-term depression. Overlay of averages of sweeps with four different recovery times (average of 8 individual responses). Dashed line represents the mean amplitude of the initial EPSC. Note that $800 \mathrm{msec}$ after the train, the response has still not recovered to baseline. Calibration: $50 \mathrm{pA}, 100$ msec. E, Data from seven neurons fit with a single exponential. Error bars represent SEM.

with $\tau_{\mathrm{m}}=10 \mathrm{msec}, R_{\mathrm{i}}=100 \mathrm{~m} \Omega$, and $V$ rest $=-80 \mathrm{mV}$. The example data for control and DA conditions shown in Figure 3 were scaled to conductance values $g_{\text {EPSC }}$ and $g_{\text {IPSC }}$. The conductance values were set to produce some spikes under control conditions, and $g_{\text {IPSC }}$ was set to twice $g_{\text {EPSC }}$ to reflect the relative abundance of symmetrical synapses on MSNs. This equation was integrated using a Euler function. If the voltage reached a threshold of $-45 \mathrm{mV}$, a spike occurred and $V_{\mathrm{m}}$ was set to +40 $\mathrm{mV}$ for $1.6 \mathrm{msec}$ and then hyperpolarized to $-60 \mathrm{mV}$ for $2.4 \mathrm{msec}$.

\section{Results}

\section{Short-term depression at excitatory and inhibitory synapses}

Pharmacologically isolated EPSCs (recorded in the presence of $100 \mu \mathrm{M}$ of the $\mathrm{GABA}_{\mathrm{A}}$ receptor antagonist picrotoxin) were recorded from MSNs in acute slices of rat NAc. In response to trains of stimuli (eight stimuli at $25 \mathrm{~Hz}$ ), EPSCs showed use-dependent short-term depression (Fig. $1 A, B$ ). The amplitude of the final EPSC in the train was $28 \pm 5 \%(n=8)$ of the first. Stimulation at multiple frequencies showed that the degree of depression is inversely dependent on the frequency of the train $(n=6)$ (Fig. 1C). To measure the recovery from short-term depression, test pulses were applied at various intervals after the train (Fig. 1D). The average recovery of seven cells was fit well by an exponential curve with a time constant of $406 \mathrm{msec}$ (Fig. $1 \mathrm{E}$ ).

Stimulation in the presence of glutamate receptor antagonists DNQX $(10 \mu \mathrm{M})$ and D-APV $(50 \mu \mathrm{M})$ produces a $\mathrm{GABA}_{\mathrm{A}}$ - 
A

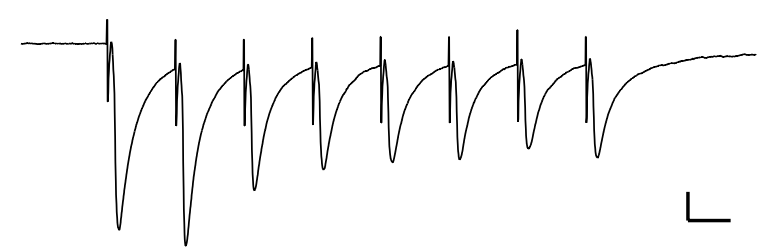

B

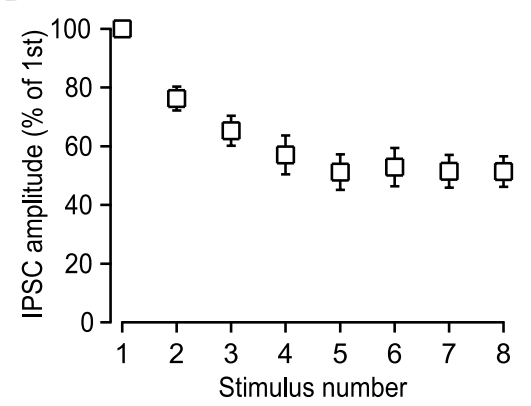

C

D

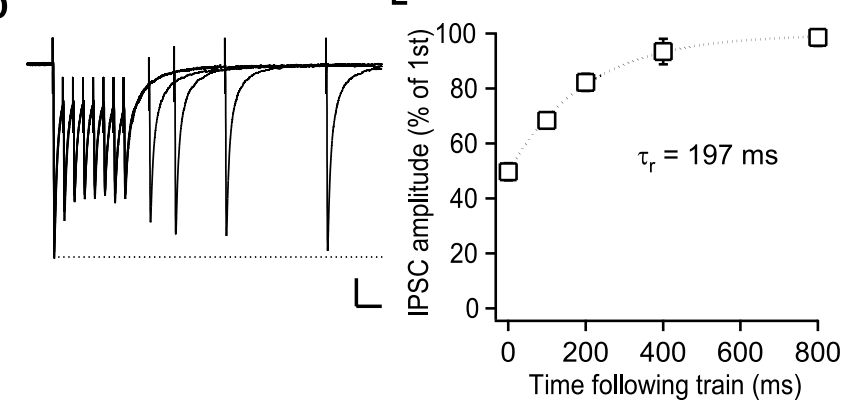

Figure 2. IPSCS also show short-term depression in response to a train. $A$, Example of a train of IPSCs (8 stimuli at $25 \mathrm{~Hz}$ ) illustrating short-term depression at this synapse. Calibration: 50 pA, 25 msec. B, Average of responses for eight cells. C, In six cells in which trains of stimuli at three different frequencies were interleaved, the amount of short-term depression is frequency dependent (repeated-measures ANOVA; $p<0.001$ ). D, Example of recovery from short-term depression. Overlay of averages of sweeps with four different recovery times (average of 8 individual responses). Dashed line represents the mean amplitude of the initial IPSC. Note that by $800 \mathrm{msec}$ after the train, the response has nearly recovered to baseline level. Calibration: 50 $\mathrm{pA}, 100 \mathrm{msec}$. E, Data from nine neurons fit with a single exponential. Error bars represent SEM.

mediated IPSC, which is recorded as an inward current when the cell is voltage clamped at $-80 \mathrm{mV}$. IPSCs also showed short-term depression in response to a train of stimuli (Fig. $2 A, B$ ), and this depression was also frequency dependent $(n=6)$ (Fig. 2C). However, the degree of depression was somewhat less than that observed for EPSCs: the amplitude of the final IPSC was $51 \pm 5 \%$ of the first $(n=8)$. Consistent with this, IPSCs showed a more rapid recovery from depression than the EPSCs (197 msec) (Fig. 2D,E).

\section{Effects of DA on short-term depression}

At synapses showing use-dependent depression, changing the probability of release alters the amplitude of the initial response but has little effect on later responses in the train (Markram et al., 1998; Selig et al., 1999). Consistent with this principle, the bath application of DA $(75 \mu \mathrm{M})$ inhibited early, but not late, EPSCs in a train (Fig. $3 A$ ). At $25 \mathrm{~Hz}$, the initial EPSC was inhibited by $51 \pm$ $10 \%$, whereas the final EPSC was only inhibited by $6 \pm 11 \%(n=$ 4). The degree of inhibition of the final stimulus exhibited strong frequency dependence (Fig. 3B): in a separate group of neurons stimulated with multiple frequencies, the last EPSC of a $10 \mathrm{~Hz}$ train was inhibited by DA, whereas at $50 \mathrm{~Hz}$, the final EPSC actually showed augmentation $(n=3)$.
A
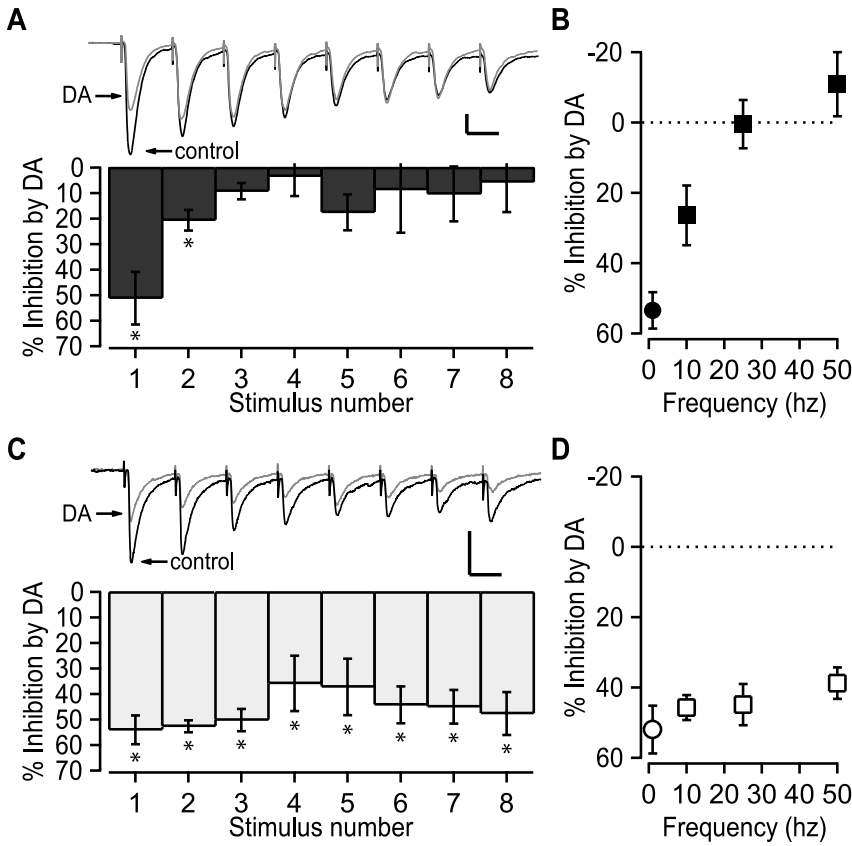

Figure 3. DA differentially modulates excitatory and inhibitory trains. A, DA preferentially inhibits early EPSCs in a train. Top traces are the average of five consecutive sweeps for control (black) and DA (gray) conditions from an example experiment. Calibration: 50 pA, $25 \mathrm{msec}$. The bar graph shows the average inhibition by DA for each EPSC in the train. ${ }^{*} p<0.05$; repeated measures ANOVA; Student-Newman-Keuls (SNK) post hoc test. $B$, The effect of DA on EPSCS shows a strong frequency dependence. Circle at $\mathrm{OHz}$ is the magnitude of inhibition of the initial EPSC. There is an overall effect of frequency on the amount of DA inhibition of the last EPSC (1-way ANOVA; $p=0.001$ ). SNK post hoc test shows that only 25 and $50 \mathrm{~Hz}$ responses are not significantly different from each other. C, DA inhibits IPSCs throughout the train. Top traces are the average of five consecutive sweeps for control (black) and DA (gray) conditions from an example experiment. Calibration: 50 pA, $25 \mathrm{msec}$. The bar graph shows the average inhibition by DA for each IPSC in the train. ${ }^{*} p<0.05$; repeated-measures ANOVA; SNK post hoc test. $D$, There is no significant effect of frequency on the amount of inhibition of the last IPSC in the train by DA. Circle at $0 \mathrm{~Hz}$ is the magnitude of inhibition of the initial IPSC. Error bars represent SEM.

Surprisingly, GABAergic synapses responded quite differently to the bath application of DA. Here, DA inhibited each of the IPSCs in a $25 \mathrm{~Hz}$ train to a similar extent: the initial IPSC was inhibited $54 \pm 6 \%$, and the final IPSC was inhibited $48 \pm 8 \%$ $(n=4)$ (Fig. 3C). Moreover, the amount of inhibition of the final IPSC was insensitive to the frequency of the train $(n=4)$ (Fig. 3D).

The inhibition of both EPSCs and IPSCs by DA was clearly antagonized by the $\mathrm{D}_{1}$ receptor antagonist SCH-23390 (10 $\left.\mu \mathrm{M}\right)$ (Fig. 4). On the other hand, the $\mathrm{D}_{2}$ receptor antagonist sulpiride $(10 \mu \mathrm{M})$ had no significant effect on the DA-mediated inhibition of either EPSCs or IPSCs.

\section{Residual calcium mediates differential effect}

There are several possible explanations for the differential effects of DA on excitatory and inhibitory trains. First, despite previous results pointing to a presynaptic effect (Nicola and Malenka, 1997), perhaps DA acts postsynaptically at GABAergic synapses. Such a mechanisms would produce a scaling effect on trains of IPSCs. However, the CV of the initial IPSC increased after application of DA $(0.15 \pm 0.02$ vs $0.27 \pm 0.03$, for control vs DA; $n=$ $8 ; p<0.01$; paired $t$ test), which is consistent with a presynaptic effect. Moreover, perfusing the postsynaptic cell with GDP- $\beta$ s (included in the whole-cell solution) did not alter the inhibition of IPSCs by DA $(n=4)$ (data not shown).

$\mathrm{CV}$ analyses do not distinguish between changes in probabil- 
A

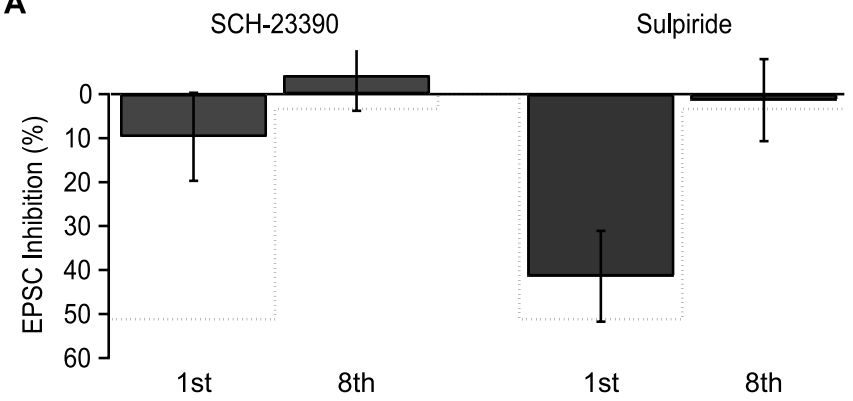

B

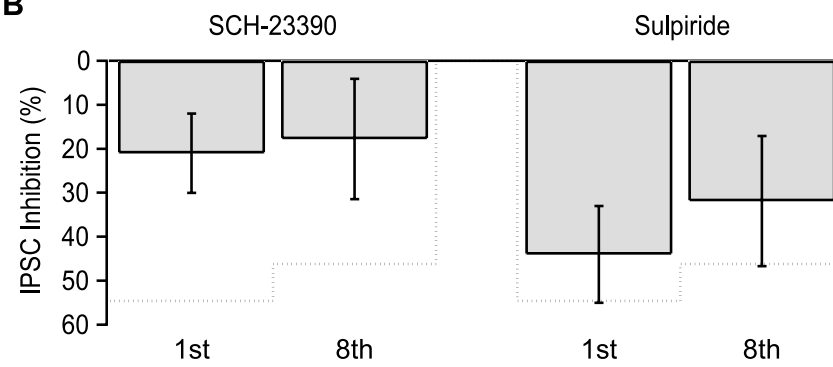

Figure 4. Effect of DA antagonists on inhibition. A, Amount of inhibition of EPSCS by DA in the presence of the $\mathrm{D}_{1}$-selective antagonist $\mathrm{SCH}-23390$ (left, $10 \mu \mathrm{m} ; n=4$ ) or the $\mathrm{D}_{2}$-selective antagonist sulpiride (right, $10 \mu \mathrm{m} ; n=3$ ). There was a significant effect of SCH-23390 ( $p<$ 0.01 ), but not of sulpiride, on the initial EPSC compared with controls. Dashed lines represent DA inhibition in control conditions. $B$, Amount of inhibition of IPSCS by DA in the presence of the $D_{1}$-selective antagonist SCH-23390 (left, $10 \mu \mathrm{m} ; n=3$ ) or the $\mathrm{D}_{2}$-selective antagonist sulpiride (right, $10 \mu \mathrm{m} ; n=3$ ). There was a significant effect of SCH-23390 on both the first and last IPSC $(p<0.01$ and $p<0.05$, respectively). There was no significant effect of sulpiride. Error bars represent SEM.

ity of release $\left(p_{\mathrm{r}}\right)$ and changes in the number of active synapses (n). Thus, DA may act on only a subset of GABA terminals but inhibit them entirely, in essence reducing $n$ but leaving the $p_{\mathrm{r}}$ of active synapses unchanged. However, bath application of a low dose of the nonselective $\mathrm{Ca}^{2+}$-channel blocker cadmium (5-10 $\mu \mathrm{M})$, which reduces the $p_{\mathrm{r}}$ at all terminals, mimicked the effect of DA on IPSCs ( $60 \pm 6$ and $51 \pm 5 \%$; first and eighth IPSC, respectively; $n=4$ ) (Fig. $5 C, D$ ). Thus, a change in $n$ is not necessary to explain the effects of DA on IPSCs.

DA inhibits transmitter release through different mechanisms at glutamatergic and GABAergic synapses (Nicola and Malenka, 1997). That is, DA inhibits glutamate release in a $\mathrm{Ca}^{2+}$ independent manner (theoretically acting on release machinery) but inhibits GABA release in a $\mathrm{Ca}^{2+}$-dependent manner (presumably by inhibiting $\mathrm{Ca}^{2+}$ entry). Perhaps these different mechanisms of inhibiting release have different effects on shortterm plasticity. To test this, I asked whether inhibiting $\mathrm{Ca}^{2+}$ entry with cadmium mimics the effect of DA at excitatory synapses. Interestingly, both early and late EPSCs were significantly inhibited by cadmium ( $46 \pm 7$ and $26 \pm 7 \%$; $n=6$ ) (Fig. $5 A, B$ ).

One possible explanation for these data is that inhibiting $\mathrm{Ca}^{2+}$ entry into the presynaptic terminal not only lowers probability of release, but also slows the recovery from use-dependent depression. This second mechanism would counter the effect of $p_{\mathrm{r}}$ on short-term depression and could explain why GABAergic synapses are inhibited throughout the train by DA. To test this, I monitored the recovery from depression of IPSCs after application of either cadmium or DA (Fig. 6). In both cases, the time constant of recovery was delayed by two- to threefold after drug application. Cadmium slowed the recovery from 159 to $376 \mathrm{msec}$ $(n=4)$, and DA slowed the recovery from 208 to $475 \mathrm{msec}(n=$
A
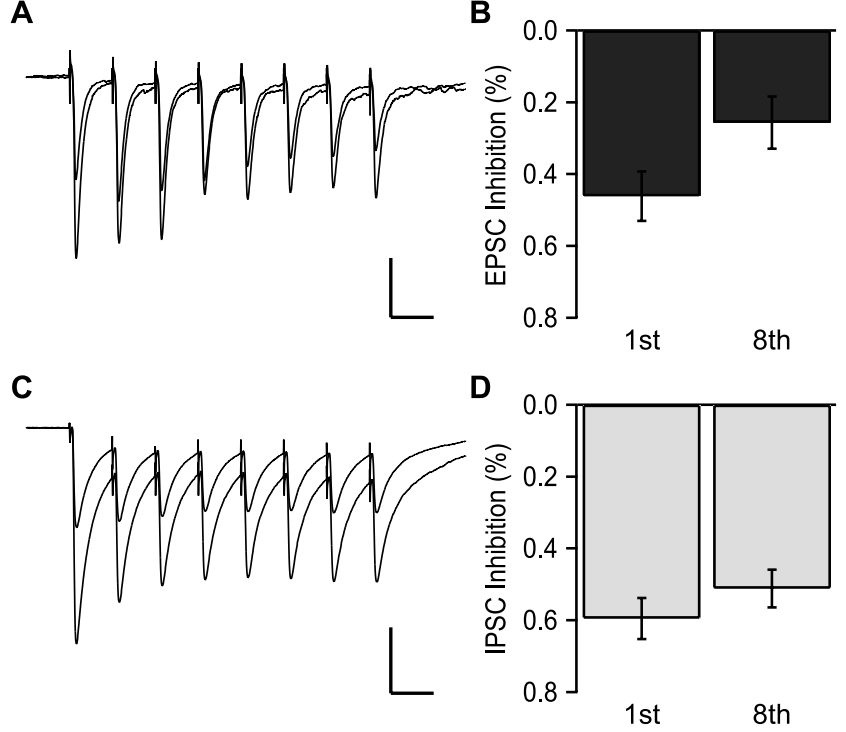

Figure 5. Effect of $\mathrm{Ca}^{2+}$ channel blockers on excitatory and inhibitory trains. A, Average of five consecutive EPSCs under control conditions and in cadmium from an example experiment. $B$, Average inhibition of the first and last EPSC in a train after the application of a low dose (5-10 $\mu \mathrm{M})$ of cadmium $(n=6)$. Both first and eighth EPSCs are significantly inhibited $(p<0.05)$. Calibration: $50 \mathrm{pA}, 40 \mathrm{msec}$. C, Average of five consecutive IPSCs under control conditions and in cadmium from an example experiment. D, Average inhibition of the first and last IPSC in a $25 \mathrm{~Hz}$ train by cadmium. Both first and eighth IPSCs are significantly inhibited ( $p<0.01)$. Calibration: 100 pA, 40 msec. Error bars represent SEM.

A

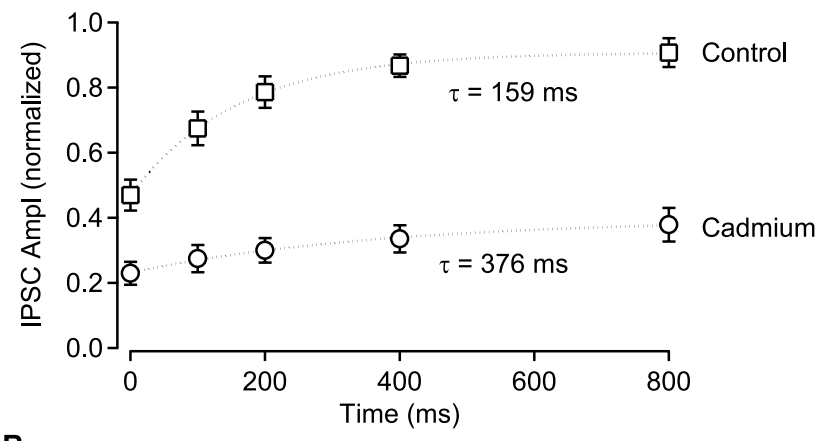

B

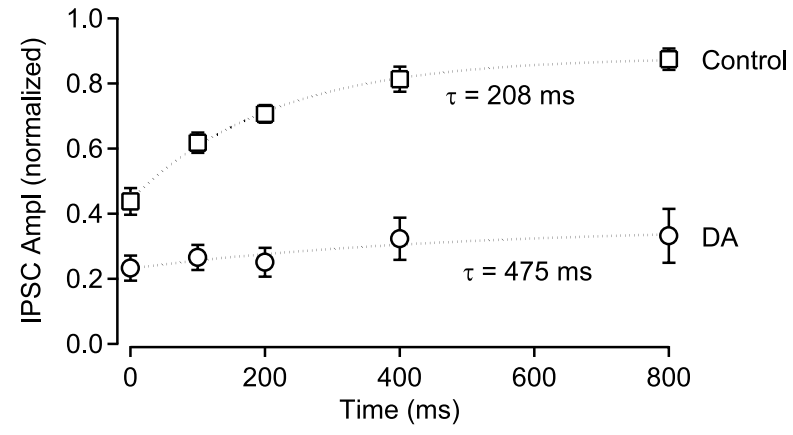

Figure 6. Effect of presynaptic inhibition on the recovery from short-term depression. $A$, The recovery from depression is slowed in the presence of cadmium $(n=4)$. Data were normalized to the initial IPSC in the train under control conditions. The data were fit with single exponentials. B, Bath application of DA $(75 \mu \mathrm{M})$ also slows the time constant of recovery $(n=5)$. Error bars represent SEM.

5). Because DA essentially abolishes use-dependent depression of EPSCs (Fig. 3A), the time constant of recovery cannot be measured. However, cadmium did slow the recovery for EPSCs $(n=$ 6) (data not shown). 
A

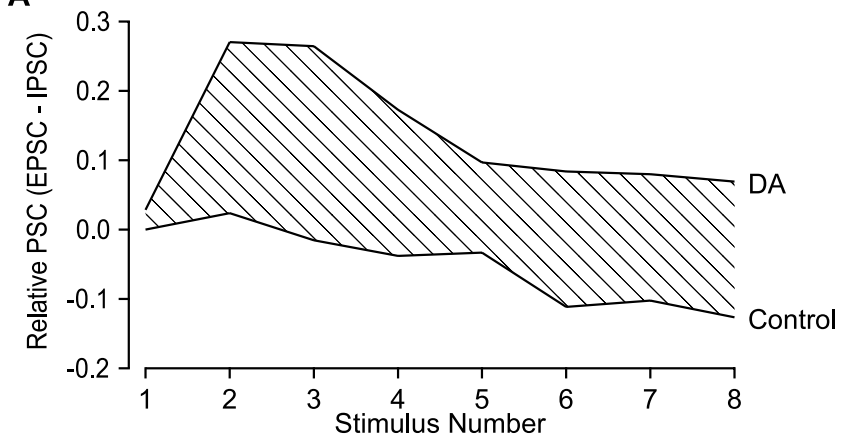

B

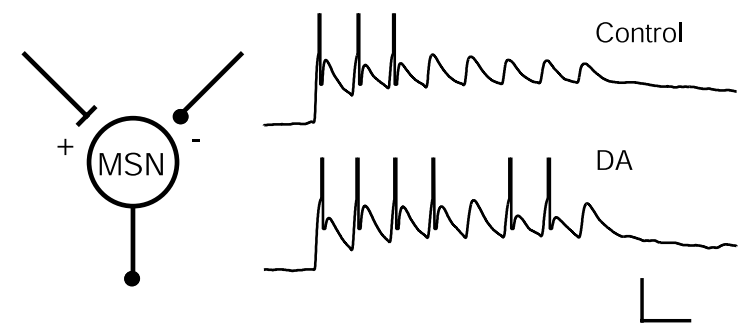

Figure 7. Net effect of DA on trains is excitation. A, The net PSC (EPSC-IPSC normalized to the initial response in the train) versus stimulus number under control conditions and in DA indicate a shift toward excitation (hatched area). $B$, Membrane voltage of an integrate-and-fire model neuron with an excitatory and an inhibitory input (left) under control conditions and in DA. Conductance changes for synaptic responses were based on the example data in Figure 3 (see Materials and Methods for details).

\section{Effect of DA on signaling in NAc}

A simple transformation of the data in Figure 3 demonstrates the net effect of DA on signaling in the NAc (Fig. 7A). Inputs onto MSNs consist of both an EPSC and an IPSC attributable to feedforward or cross inhibition. Under normal conditions, this net PSC (defined as EPSC-IPSC) will shift toward inhibition later in a train, because the GABA synapses show less short-term depression than the glutamate synapses. In the presence of DA, however, the GABA synapses will be inhibited throughout the train, whereas the glutamate synapses are not; thus, the train will produce an excitatory PSC. Thus, the net effect of DA (Fig. 7A, hatched area) is to produce excitation.

This effect can be more fully illustrated with a simple integrate-and-fire model neuron that receives two inputs: an excitatory input (reversal potential of $0 \mathrm{mV}$ ) and an inhibitory input (reversal potential of $-60 \mathrm{mV}$ ). The conductance change produced by the two synaptic inputs during repetitive stimulation was based on the example data shown in Figure 3 and were scaled so that, under control conditions, the model cell responded with a few action potentials (Fig. 7B). DA increased the number of action potential in response to the train. Importantly, later stimuli, which were subthreshold under control conditions, now responded with an action potential.

To test the predictions of this model in the slice, I recorded neurons in cell-attached mode (to avoid interfering with the intracellular composition). Both excitatory and inhibitory synaptic transmission were left intact, and the stimulation intensity was set to evoke two to three spikes in response to a train of stimuli. Bath application of DA caused a clear increase in the number of spikes evoked per train $(n=3)$ (Fig. $8 A$ ). Moreover, the distribution of action potentials shifted toward the later stimuli (Fig. $8 B$ ).

The net excitation resulting in additional action potentials is
A

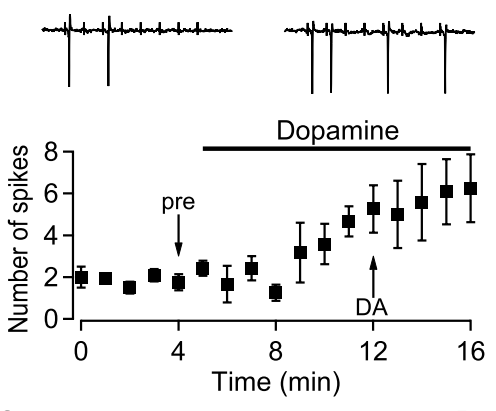

C

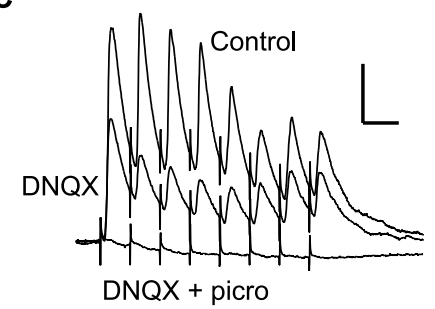

D

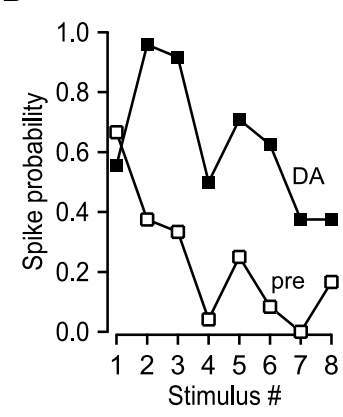

Subtracted

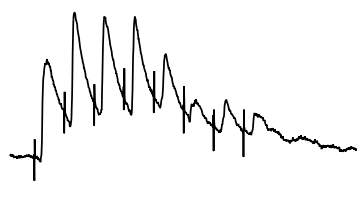

Figure 8. DA increases spike probability. $A$, Top traces are individual traces from a cell-attached experiment during baseline (left) and in DA (right). Below is average of three experiments showing number of spikes in response to a train of eight stimuli at $25 \mathrm{~Hz}$. Error bars represent SEM. B, Average probability of a spike for each stimulus in the train under control conditions (open symbols) and in DA (closed symbols). Data were calculated from a 2 min epoch represented by the arrows in A. C, IPSC recorded at $+5 \mathrm{mV}$ under control conditions, in the presence of DNQX (10 $\mu \mathrm{M})$, and DNQX plus picrotoxin $(100 \mu \mathrm{m})$. Calibration: $100 \mathrm{pA}, 50 \mathrm{msec}$. D, The polysynaptic IPSC is determined by subtracting the IPSC recorded in DNQX from the control IPSC.

caused by the inhibition of GABA release. However, it is not clear whether the GABAergic neurons producing feedforward inhibition follow trains of inputs. If excitatory transmission is intact, stimulation in the slice evokes both monosynaptic IPSCs as well as polysynaptic feedforward inhibition. To determine the polysynaptic response, neurons were held at the reversal potential for AMPA-NMDA receptors $(\sim 0-5 \mathrm{mV})$. Thus, although glutamate transmission is intact, the recorded response is entirely GABAergic (Fig. 8C). Addition of DNQX (10 $\mu \mathrm{M})$ blocked the polysynaptic IPSC, leaving only the monosynaptic component. Finally, the addition of picrotoxin blocked this monosynaptic IPSC, leaving only the NMDA receptor-mediated EPSC to confirm that the cell was held at the EPSC reversal potential. By subtracting the monosynaptic IPSC from the control IPSC, the polysynaptic component is revealed (Fig. $8 D$ ). The relative magnitude of the polysynaptic IPSC (compared with the monosynaptic IPSC) varied; however, the polysynaptic IPSC clearly responded to each of the stimuli in the train $(n=4)$, indicating that the GABAergic interneurons can clearly follow trains of stimulation.

\section{Discussion}

In this study, I have shown that, despite inhibiting glutamate release, DA can have an excitatory effect in the NAc. This is because the inhibition of GABA persists throughout trains of stimuli, whereas the inhibition of glutamate does not. Thus, DA produces a net excitation that grows throughout a train.

Both EPSCs and IPSCs in the NAc show short-term usedependent synaptic depression in response to trains of stimuli. This is a common phenomenon that has been extensively studied at many different synapses (Zucker and Regehr, 2002). Although the precise mechanisms of this depression are unclear, it is consistent with the depletion of the readily releasable pool of vesicles 
caused by synaptic release. Thus, two factors control the degree of depression: the rate of refilling of the vesicle pool and the probability of release (of available vesicles). Manipulations that lower the probability of release result in a slower exhaustion of the vesicle pool, producing less short-term depression. As a result, the amplitude of responses later in a train is unaffected by manipulating the probability of release. This is a hallmark of use-dependent depression (Tsodyks and Markram, 1997; Selig et al., 1999).

Not every synapse that shows short-term depression behaves in this manner. For example, at the basket cell $\rightarrow$ granule cell synapse in the dentate gyrus of the hippocampus, reducing the probability of release leaves short-term depression of IPSCs unchanged (Hefft et al., 2002). This can be explained if the shortterm depression is independent of transmitter release, but rather is simply dependent on the activity of the presynaptic axon (Kim and Alger, 2001; Hefft et al., 2002). Alternatively, if the manipulation changing the probability of release additionally alters the rate of recovery from depression, a similar result would be obtained.

Dopamine reduces the probability of release of both glutamate and GABA in the NAc. However, this occurs through different mechanisms (Nicola and Malenka, 1997). GABA release is inhibited in a $\mathrm{Ca}^{2+}$-dependent manner, theoretically as a result of the inhibition of $\mathrm{Ca}^{2+}$ entry into the terminal. The inhibition of glutamate is $\mathrm{Ca}^{2+}$ independent, occurring downstream of $\mathrm{Ca}^{2+}$ entry. Despite these different mechanisms, in response to single stimuli, DA appears to have a comparable effect on release (Nicola and Malenka, 1997). This is confirmed in the present study with the analysis of the initial EPSC or IPSC in a train. However, because of their different mechanisms, DA differentially affects the residual $\mathrm{Ca}^{2+}$ at these two synapses. Thus, any $\mathrm{Ca}^{2+}$-dependent processes in the terminal will be differentially modulated by DA. Most notably, this could impact $\mathrm{Ca}^{2+}$ dependent recovery from depression, a process that has been studied at a number of synapses, including the climbing fiber synapse onto Purkinje cells in the cerebellum (Dittman and Regehr, 1998), the calyx of Held synapse (Wang and Kaczmarek, 1998), as well as autapses on cultured hippocampal neurons (Stevens and Wesseling, 1998). Specifically, residual $\mathrm{Ca}^{2+}$ speeds up the recovery from short-term depression at synapses, apparently by accelerating the replenishment of the readily releasable pool of vesicles. During a train of stimuli, this action of $\mathrm{Ca}^{2+}$ will result in less short-term depression. Reducing residual $\mathrm{Ca}^{2+}$ slows this recovery toward a baseline rate and increases shortterm depression. At inhibitory synapses in the NAc, by inhibiting $\mathrm{Ca}^{2+}$ entry, DA concurrently reduces the probability of release and slows the recovery from depression. These two actions counteract each other, resulting in a consistent degree of short-term depression in the presence and absence of DA.

It should be noted that the exact mechanisms of usedependent depression have not been firmly established, and moreover, may differ at different synapses. For example, the change in recovery may not reflect refilling of the readily releasable pool but could also reflect other processes such as recovery from receptor desensitization.

Unlike the NAc, DA does not appear to inhibit synaptic transmission in the dorsal striatum (Nicola et al., 2000). However, these experiments did not use trains of stimuli. A recent study using the fluorescent dye FM1-43 ( $N$-(3-triethylammoniumpropyl)-4-(4-(dibutylamino)styryl) pyridinium dibromide) to monitor synaptic activity did observe $\mathrm{a}_{2}$-dependent inhibition of release (Bamford et al., 2004). Importantly, this inhibition was frequency dependent, being greater at higher frequencies. Interestingly, Bamford et al. (2004) suggest that their results could be attributable to a DA-dependent slowing of the recovery from depression. There are fundamental differences between the presynaptic effects of DA in the dorsal and ventral striatum. In the NAc, low-frequency release is inhibited by DA, whereas in the dorsal striatum, it is not. In the NAc, the inhibition is mediated by $D_{1}$ receptors, whereas in the dorsal striatum, it is mediated by $D_{2}$. Finally, in the NAc, DA appears to alter recovery only at GABA terminals, whereas the Bamford et al. (2004) study is consistent with a change in recovery at glutamate terminals. However, despite the differences, these studies illustrate that the presynaptic effects of DA can be more complex than simply reducing the probability of release.

Excitatory afferent activity in the NAc engages feedforward inhibition (Pennartz and Kitai, 1991). However, it is not clear how faithfully the GABA neurons in this circuit follow the excitatory inputs. MSNs, which collateralize within the NAc, do not fire action potentials in response to each stimulus (although this will depend on the convergence of concurrently active inputs). However, the majority of NAc inhibition appears to come from a small population of interneurons (Koos and Tepper, 1999) that fire at higher rates and follow excitatory inputs with higher fidelity. Interestingly, because of the frequency independence of the effects of DA, GABA release will be inhibited independent of the firing rate of the GABAergic interneurons. As long as there is some GABA release (as has been demonstrated here), the net effect of DA will be excitatory.

DA is released in the NAc in response to cues that predict reward (Roitman et al., 2004). This release is thought to promote the selection of the appropriate motor responses necessary to obtain the reward. Theoretically, this occurs by enhancing the contrast between competing inputs, making it easier for the strongest inputs to activate MSNs. Mechanisms to explain this enhancement have been proposed (Schultz, 2002; Nicola et al., 2004 b), based primarily on postsynaptic effects of DA in the dorsal striatum. However, it is clear that DA has different effects in the dorsal striatum and the NAc (Nicola et al., 2000). The differential inhibition of release at glutamatergic and GABAergic terminals by DA described here provides a simple mechanism for enhancing the contrast of inputs into NAc. Specifically, longer, higher-frequency bursts, presumably encoding more salient information, will be excited to a greater degree than shorter, slower (and less salient) bursts.

The NAc is also a key substrate for the learning of cue-reward relationships (Cador et al., 1989; Parkinson et al., 1999, 2000; Hutcheson et al., 2001). Specifically, both DA and NMDA receptors in the NAc are necessary for this learning (Kelley et al., 1997; Smith-Roe and Kelley, 2000; Di Ciano et al., 2001; Parkinson et al., 2002). For example, either the NMDA receptor antagonist D-APV or the $\mathrm{D}_{1}$ receptor antagonist SCH-23390 blocks the acquisition of lever-pressing for sucrose pellets in rats (Kelley et al., 1997; Smith-Roe and Kelley, 2000). Based on these behavioral results, as well as the anatomical proximity between DA terminals and glutamate synapses (Sesack and Pickel, 1992), it has been proposed that DA acts to gate synaptic plasticity in the NAc. However, in vitro plasticity studies have not established a link between DA and NMDAR-dependent plasticity, such as longterm potentiation (LTP) or long-term depression (Pennartz et al., 1993; Thomas et al., 2000), or have observed a loss of LTP (Li and Kauer, 2004). Notably, these studies with DA were conducted in the presence of $\mathrm{GABA}_{\mathrm{A}}$ receptor antagonists. If inhibi- 
tion were left intact, high-frequency stimulation would produce a larger NMDA current in the presence of DA caused by the inhibition of GABA release, thereby facilitating synaptic plasticity. Indeed, in agreement with studies in the hippocampus (Wigstrom and Gustafsson, 1983), inhibiting GABA release in the NAc facilitates LTP (Pennartz et al., 1993).

In vitro electrophysiology studies in the NAc typically look at synaptic responses to single or, at most, paired stimuli. However, it is increasingly clear that relevant information into the NAc are carried by bursts of action potentials (Cooper, 2002). In the present study, I show that the presynaptic effects of DA strongly depend on the temporal history of their inputs. These data provide a possible mechanism that could underlie the role of DA in the nucleus accumbens both on choosing and on learning.

\section{References}

Bamford NS, Zhang H, Schmitz Y, Wu NP, Cepeda C, Levine MS, Schmauss C, Zakharenko SS, Zablow L, Sulzer D (2004) Heterosynaptic dopamine neurotransmission selects sets of corticostriatal terminals. Neuron 42:653-663.

Cador M, Robbins TW, Everitt BJ (1989) Involvement of the amygdala in stimulus-reward associations: interaction with the ventral striatum. Neuroscience 30:77-86.

Chang HT, Kitai ST (1985) Projection neurons of the nucleus accumbens: an intracellular labeling study. Brain Res 347:112-116.

Cooper DC (2002) The significance of action potential bursting in the brain reward circuit. Neurochem Int 41:333-340.

Di Ciano P, Cardinal RN, Cowell RA, Little SJ, Everitt BJ (2001) Differential involvement of NMDA, AMPA/kainate, and dopamine receptors in the nucleus accumbens core in the acquisition and performance of Pavlovian approach behavior. J Neurosci 21:9471-9477.

Dittman JS, Regehr WG (1998) Calcium dependence and recovery kinetics of presynaptic depression at the climbing fiber to Purkinje cell synapse. J Neurosci 18:6147-6162.

Dittman JS, Kreitzer AC, Regehr WG (2000) Interplay between facilitation, depression, and residual calcium at three presynaptic terminals. J Neurosci 20:1374-1385.

Ghitza UE, Fabbricatore AT, Prokopenko V, Pawlak AP, West MO (2003) Persistent cue-evoked activity of accumbens neurons after prolonged abstinence from self-administered cocaine. J Neurosci 23:7239-7245.

Hefft S, Kraushaar U, Geiger JR, Jonas P (2002) Presynaptic short-term depression is maintained during regulation of transmitter release at a GABAergic synapse in rat hippocampus. J Physiol (Lond) 539:201-208.

Hopf FW, Cascini MG, Gordon AS, Diamond I, Bonci A (2003) Cooperative activation of dopamine $D_{1}$ and $D_{2}$ receptors increases spike firing of nucleus accumbens neurons via G-protein $\beta \gamma$ subunits. J Neurosci 23:5079-5087.

Hutcheson DM, Parkinson JA, Robbins TW, Everitt BJ (2001) The effects of nucleus accumbens core and shell lesions on intravenous heroin selfadministration and the acquisition of drug-seeking behaviour under a second-order schedule of heroin reinforcement. Psychopharmacology (Berl) 153:464-472.

Jung MW, Qin Y, McNaughton BL, Barnes CA (1998) Firing characteristics of deep layer neurons in prefrontal cortex in rats performing spatial working memory tasks. Cereb Cortex 8:437-450.

Kawaguchi Y, Wilson CJ, Augood SJ, Emson PC (1995) Striatal interneurones: chemical, physiological and morphological characterization. Trends Neurosci 18:527-535.

Kelley AE, Smith-Roe SL, Holahan MR (1997) Response-reinforcement learning is dependent on $N$-methyl-D-aspartate receptor activation in the nucleus accumbens core. Proc Natl Acad Sci USA 94:12174-12179.

Kim J, Alger BE (2001) Random response fluctuations lead to spurious paired-pulse facilitation. J Neurosci 21:9608-9618.

Koos T, Tepper JM (1999) Inhibitory control of neostriatal projection neurons by GABAergic interneurons. Nat Neurosci 2:467-472.
Li Y, Kauer JA (2004) Repeated exposure to amphetamine disrupts dopaminergic modulation of excitatory synaptic plasticity and neurotransmission in nucleus accumbens. Synapse 51:1-10.

Markram H, Pikus D, Gupta A, Tsodyks M (1998) Potential for multiple mechanisms, phenomena and algorithms for synaptic plasticity at single synapses. Neuropharmacology 37:489-500.

McClure SM, Daw ND, Montague PR (2003) A computational substrate for incentive salience. Trends Neurosci 26:423-428.

Nicola SM, Malenka RC (1997) Dopamine depresses excitatory and inhibitory synaptic transmission by distinct mechanisms in the nucleus accumbens. J Neurosci 17:5697-5710.

Nicola SM, Malenka RC (1998) Modulation of synaptic transmission by dopamine and norepinephrine in ventral but not dorsal striatum. J Neurophysiol 79:1768-1776.

Nicola SM, Surmeier J, Malenka RC (2000) Dopaminergic modulation of neuronal excitability in the striatum and nucleus accumbens. Annu Rev Neurosci 23:185-215.

Nicola SM, Yun IA, Wakabayashi KT, Fields HL (2004a) Cue-evoked firing of nucleus accumbens neurons encodes motivational significance during a discriminative stimulus task. J Neurophysiol 91:1840-1865.

Nicola SM, Hopf FW, Hjelmstad GO (2004b) Contrast enhancement: a physiological effect of striatal dopamine? Cell Tissue Res, in press.

Parkinson JA, Olmstead MC, Burns LH, Robbins TW, Everitt BJ (1999) Dissociation in effects of lesions of the nucleus accumbens core and shell on appetitive pavlovian approach behavior and the potentiation of conditioned reinforcement and locomotor activity by D-amphetamine. J Neurosci 19:2401-2411.

Parkinson JA, Willoughby PJ, Robbins TW, Everitt BJ (2000) Disconnection of the anterior cingulate cortex and nucleus accumbens core impairs Pavlovian approach behavior: further evidence for limbic cortical-ventral striatopallidal systems. Behav Neurosci 114:42-63.

Parkinson JA, Dalley JW, Cardinal RN, Bamford A, Fehnert B, Lachenal G, Rudarakanchana N, Halkerston KM, Robbins TW, Everitt BJ (2002) Nucleus accumbens dopamine depletion impairs both acquisition and performance of appetitive Pavlovian approach behaviour: implications for mesoaccumbens dopamine function. Behav Brain Res 137:149-163.

Pennartz CM, Kitai ST (1991) Hippocampal inputs to identified neurons in an in vitro slice preparation of the rat nucleus accumbens: evidence for feed-forward inhibition. J Neurosci 11:2838-2847.

Pennartz CM, Dolleman-Van der Weel MJ, Kitai ST, Lopes da Silva FH (1992) Presynaptic dopamine D1 receptors attenuate excitatory and inhibitory limbic inputs to the shell region of the rat nucleus accumbens studied in vitro. J Neurophysiol 67:1325-1334.

Pennartz CM, Ameerun RF, Groenewegen HJ, Lopes da Silva FH (1993) Synaptic plasticity in an in vitro slice preparation of the rat nucleus accumbens. Eur J Neurosci 5:107-117.

Pennartz CM, Groenewegen HJ, Lopes da Silva FH (1994) The nucleus accumbens as a complex of functionally distinct neuronal ensembles: an integration of behavioural, electrophysiological and anatomical data. Prog Neurobiol 42:719-761.

Roitman MF, Stuber GD, Phillips PE, Wightman RM, Carelli RM (2004) Dopamine operates as a subsecond modulator of food seeking. J Neurosci 24:1265-1271.

Schultz W (1998) Predictive reward signal of dopamine neurons. J Neurophysiol 80:1-27.

Schultz W (2002) Getting formal with dopamine and reward. Neuron 36:241-263.

Schultz W, Tremblay L, Hollerman JR (2000) Reward processing in primate orbitofrontal cortex and basal ganglia. Cereb Cortex 10:272-284.

Selig DK, Nicoll RA, Malenka RC (1999) Hippocampal long-term potentiation preserves the fidelity of postsynaptic responses to presynaptic bursts. J Neurosci 19:1236-1246.

Sesack SR, Pickel VM (1992) Prefrontal cortical efferents in the rat synapse on unlabeled neuronal targets of catecholamine terminals in the nucleus accumbens septi and on dopamine neurons in the ventral tegmental area. J Comp Neurol 320:145-160.

Smith-Roe SL, Kelley AE (2000) Coincident activation of NMDA and dopamine $D_{1}$ receptors within the nucleus accumbens core is required for appetitive instrumental learning. J Neurosci 20:7737-7742. 
Stevens CF, Wesseling JF (1998) Activity-dependent modulation of the rate at which synaptic vesicles become available to undergo exocytosis. Neuron 21:415-424.

Taverna S, Van Dongen YC, Groenewegen HJ, Pennartz CM (2004) Direct physiological evidence for synaptic connectivity between medium-sized spiny neurons in rat nucleus accumbens in situ. J Neurophysiol 91:1111-1121.

Thomas MJ, Malenka RC, Bonci A (2000) Modulation of long-term depression by dopamine in the mesolimbic system. J Neurosci 20:5581-5586.

Tsodyks MV, Markram H (1997) The neural code between neocortical pyramidal neurons depends on neurotransmitter release probability. Proc Natl Acad Sci USA 94:719-723.
Uchimura N, Cherubini E, North RA (1989) Inward rectification in rat nucleus accumbens neurons. J Neurophysiol 62:1280-1286.

Wang LY, Kaczmarek LK (1998) High-frequency firing helps replenish the readily releasable pool of synaptic vesicles. Nature 394:384-388.

Wigstrom H, Gustafsson B (1983) Facilitated induction of hippocampal long-lasting potentiation during blockade of inhibition. Nature 301:603-604.

Yun IA, Wakabayashi KT, Fields HL, Nicola SM (2004) The ventral tegmen$\mathrm{tal}$ area is required for the behavioral and nucleus accumbens neuronal firing responses to incentive cues. J Neurosci 24:2923-2933.

Zucker RS, Regehr WG (2002) Short-term synaptic plasticity. Annu Rev Physiol 64:355-405. 